\title{
Medicalisation of Birth in Transylvania in the Second Half of the 19th Century. A Subject to be Investigated
}

By Luminiţa Dumănescu and Ioan Bolovan

To cite this article: Dumănescu, L. \& Bolovan, I. (2021). Medicalisation of Birth in Transylvania in the Second Half of the 19th Century. A Subject to be Investigated. Historical Life Course Studies, 10, 91-95. https://doi.org/10.51964/hlcs9574

\section{HISTORICAL LIFE COURSE STUDIES}

Not Like Everybody Else.

Essays in Honor of Kees Mandemakers

VOLUME 10, SPECIAL ISSUE 3

2021

GUEST EDITORS

Hilde Bras

Jan Kok

Richard L. Zijdeman 


\section{HISTORICAL LIFE COURSE STUDIES}

Historical Life Course Studies is the electronic journal of the European Historical Population Samples Network (EHPSNet). The journal is the primary publishing outlet for research involved in the conversion of existing European and nonEuropean large historical demographic databases into a common format, the Intermediate Data Structure, and for studies based on these databases. The journal publishes both methodological and substantive research articles.

\section{Methodological Articles}

This section includes methodological articles that describe all forms of data handling involving large historical databases, including extensive descriptions of new or existing databases, syntax, algorithms and extraction programs. Authors are encouraged to share their syntaxes, applications and other forms of software presented in their article, if pertinent, on the openjournals website.

\section{Research articles}

This section includes substantive articles reporting the results of comparative longitudinal studies that are demographic and historical in nature, and that are based on micro-data from large historical databases.

Historical Life Course Studies is a no-fee double-blind, peer-reviewed open-access journal supported by the European Science Foundation (ESF, http://www.esf.org), the Scientific Research Network of Historical Demography (FWO Flanders, http://www.historicaldemography.be) and the International Institute of Social History Amsterdam (IISH, http://socialhistory.org/). Manuscripts are reviewed by the editors, members of the editorial and scientific boards, and by external reviewers. All journal content is freely available on the internet at https://openjournals.nl/index.php/hlcs.

\section{Co-Editors-In-Chief:}

Paul Puschmann (Radboud University) \& Luciana Quaranta (Lund University)

hislives@kuleuven.be

The European Science Foundation (ESF) provides a platform for its Member Organisations to advance science and explore new directions for research at the European level. Established in 1974 as an independent non-governmental organisation, the ESF currently serves 78 Member Organisations across 30 countries. EHPS-Net is an ESF Research Networking Programme.

The European Historical Population Samples Network (EHPS-net) brings together scholars to create a common format for databases containing non-aggregated information on persons, families and households. The aim is to form an integrated and joint interface between many European and non-European databases to stimulate comparative research on the micro-level.

Visit: http://www.ehps-net.eu.
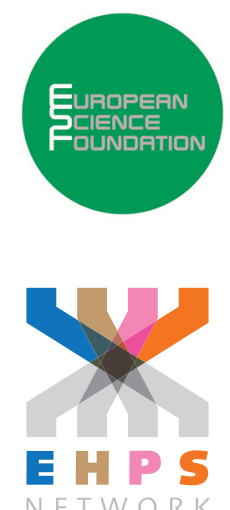


\title{
Medicalisation of Birth in Transylvania in the Second Half of the 19th Century
}

\section{A Subject to be Investigated}

\author{
Luminiţa Dumănescu \\ Babeş-Bolyai University, Cluj-Napoca \\ Ioan Bolovan \\ Babeş-Bolyai University, Cluj-Napoca
}

\begin{abstract}
The role played by midwives during modernity deserves increased attention. Ethnic and confessional minorities often displayed starkly different patterns in the selection of these instrumental figures. More than that, the differences between the official reports and the community behavior recorded at ground level suggest a major gap between theory and practice. In theory, the province of Transylvania was well provided with medical care, midwives included. Data collected into the Historical Population Database of Transylvania reveals the fact that most women were assisted at birth by handywomen, the traditional, unskilled midwives. A research tool like a historical population database could help the scholars to address the issue of birth medicalisation, starting from the main research question: can we discuss the medicalisation of birth given that more than half of the women assisted in the delivery of just one child?
\end{abstract}

Keywords: Midwives, Birth medicalisation, HPDT

e-ISSN: $\quad$ 2352-6343

DOI article: $\quad$ https://doi.org/10.51964/hlcs9574

The article can be downloaded from here.

(C) 2021, Dumănescu, Bolovan

This open-access work is licensed under a Creative Commons Attribution 4.0 International License, which permits use, reproduction \& distribution in any medium for non-commercial purposes, provided the original author(s) and source are given credit. See http://creativecommons.org/licenses/. 


\section{INTRODUCTION}

The development of the Historical Population Database of Transylvania (HPDT) ${ }^{1}$ provided the tool for researching demographic phenomena at the micro level of the province. The newly available data allow scholars to dive into the intimacy of a world which turns out to have functioned and to have been organised differently from how it was previously considered to have done based on micro-level analyses. These sources shape a social history which sheds new light on the old world — often considered obsolete and traditional of a province situated at the periphery of a great Empire. In this way, as an example, it became apparent that the tradition of women acquiring their husbands' surnames upon marriage is not as old as had previously been believed. Many Transylvanian women, living in Roman Catholic, Protestant and Orthodox communities alike, continued to be known and referred to in society and official documents with their fathers' surnames. How else could it be explained that upon the marriage of their children, and therefore at least twenty years after their own weddings, the mothers-in-law are still registered with their maiden names? This habit of husband and wife not sharing a family name can also be noticed at the birth of their children or the registration of the woman's death. A study addressing this issue has recently been submitted for publication and we hope to see it in circulation as soon as possible.

Another issue which attracts researchers' interest is the medicalisation of birth. The source data entered into the HPDT ranges from 1850 to 1914, its main sources being vital registrations (baptisms, marriages, burials) which were recorded and kept by the church. These were the only official documents of civil status prior to 1895, when the state introduced its own system of civil registration and entrusted trained functionaries with the mission of registering the important events of private life. Therefore, these registries are nothing but the reflection of the society which produced them - a reflection oftentimes chiselled by the priest of the village, through the hands of whom all destinies in the parish passed. The interest in this subject was sparked by the abundance of midwives registered in the database, this being in accordance with the official Hungarian statistic which showed a relatively good coverage of medical personnel, midwives included, throughout the second half of the 19th century. Over a period of 50 years thousands of women were marked as 'midwives' in the parish registries, which has posed several questions: who are these midwives? Were they truly 'midwives'? Were they among those medically trained as 'midwives' or were they merely women assisting at births? Did they acquire their craft through organised courses, attending medical schools, or by serving as apprentices to the old village midwives, carefully observing their techniques? Can we really have a discussion about the medicalisation of birth at the end of the 19th century and the beginning of the 20th given that there were thousands of women marked as 'midwives', often more than a hundred in a single village? Considering the existence of necessary legislation (see Dumănescu \& Eppel, 2019), how can the absence of effects of this legislation be explained? The difference between theory and practice, respectively the difference between the official Hungarian statistics and the situation on the ground, seems to be quite evident in this matter.

\section{DATA AND FINDINGS}

The HPDT data shows that, in the second half of the 19th century, the medicalisation of birth remained only in the official reports, being a reality - probably — only in towns and boroughs. The great majority of the population continued to use traditional, unskilled midwives or relied on the help of neighbours and relatives during the time of birthing.

For this exploratory paper we used the data included in the HPDT for the period 1850-1918, while focusing on Orthodox, Roman Catholic, Greek Catholic, Reformed, Lutheran and Jewish communities. In the database there are recorded 50,636 events of birth, assisted by 3,165 midwives. Eliminating from our sample the birth events with incomplete information (namely, instances in which the name of the midwife was not registered, or she cannot be identified), we analysed 2855 midwives, belonging to all mentioned denominations and living in 35 villages for which the information concerning the birth of children was registered in 95 parish registries.

1 The Historical Population Database of Transylvania was developed by the Centre for Population Studies in Cluj-Napoca and follows the best practices model for constructing historical population databases outlined by Mandemakers and Dillon (2004). We remain deeply indebted to Kees Mandemakers for all his support in writing the project proposal in 2013, implementing the database and spreading the results! 
Figure 1

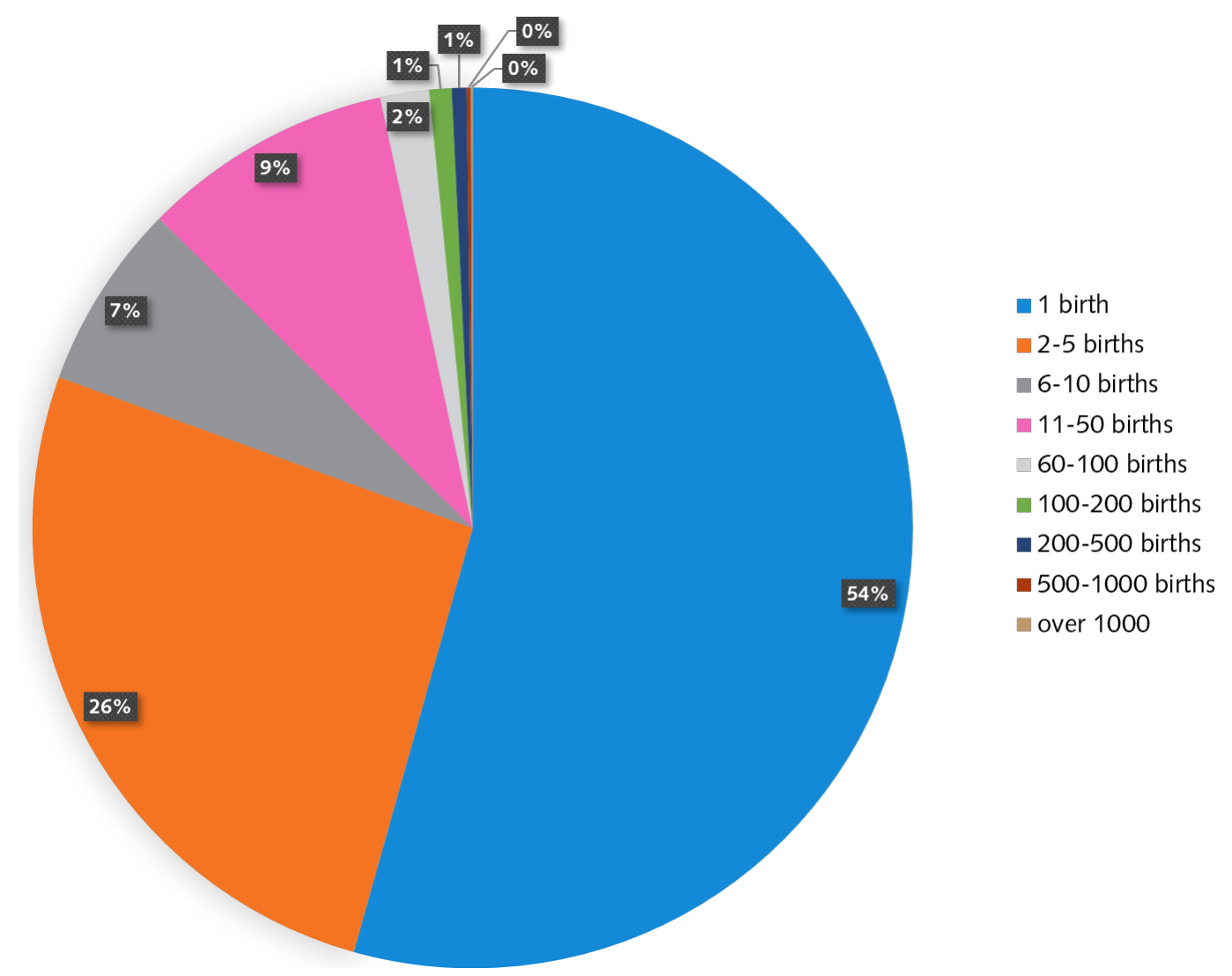

Source: HPDT

More than half of the women registered as midwives took part in the act of birthing once in their lives, which means they were in fact 'handywomen' - neighbours or relatives who happened to be around the mother to be and helped deliver the child. Moreover, only 80 out of the 2,855 midwives took part in over 10 birth events and only about two can be said with certainty, at this stage, to have been 'official' midwives, paid by the community. These women attended over 1,000 birth events and women of all confessions benefited from their services.

It was noticed that the midwives recorded most frequently in the parish registries came from Ocna Mureş, a town in full ascension in the second half of the 19th century (Holom, Sorescu-ludean, Hărăguş, 2018). This town has many of the well-known urban characteristics of the era, an important part of its population working in the mining industry. Moreover, the town was not a tourist location.

In chronological order, the midwives serving Ocna Mureş were:

- Anna Kaszannoa, Ocna Mureş, 1834-1853, 718 assisted births — only for Greek Catholics

- Sarolta Kovács, Ocna Mureş, 1864-1897, 856 assisted births - for all denominations in town (Calvinists, Greek Catholics and even Jewish mothers)

- Fráncziska Petersberger, Ocna Mureş, 1876-1899, 1385 assisted births for all denominations. Beside her name, on multiple occasions, the note 'diplomatic midwife' can be seen - it is thus unsurprising that she was called to help all kinds of women, regardless of confession or ethnicity.

An extremely interesting situation can be noticed in Călăraşi-Turda, another multi-ethnic and multiconfessional community, where great trust was placed in the services of a Hungarian midwife, Csorba Rhachel, who attended 872 births between 1863 and 1895. She assisted the Orthodox and Roman Catholic communities alike. In 1850, at the age of 19, she married Janos Szabo from Harasztos, both of them being Roman Catholic. Thus, in 1863 when she was first registered as midwife, she was already 32 years old and she continued in the occupation until the age of 65. She died in 1897, two years after the last occasion on which she was registered as midwife. In 1874, she lost two children. Unfortunately, for both cases the cause 
of death is registered as 'morbus communis' [natural death], although the children were aged 3 years and 1 and a half years respectively.

Maria Nagy, from Călăraşi-Turda, has 433 associated births between 1879 and 1909. For more than 15 years, her work overlapped with that of Rachel Csorba, the communities they assisted being the same (Orthodox, Roman Catholic, Greek Catholic).

Midwives called on to assist only the births of women from the same confession as themselves can also be found. Ana Mărginean, for instance, assisted 169 births between 1870 and 1879 . However, a very interesting observation can be made: out of the 10 midwives who assisted more than 10 births in CălăraşiTurda, the Orthodox midwives (4) were recorded only in the registries belonging to the Orthodox parishes, whereas the Catholic midwives were recorded in the registries of all confessions. The question remains open as to whether this situation was due to the midwives' refusal to assist women outside their confession, or the pregnant women's wish to be assisted at the birth by women of the same religion as themselves. It is however certain that many Orthodox women - thus, Romanian - benefited from the assistance of Hungarian Catholic midwives while in labour. Rachel Csorba assisted 258 Orthodox and Greek Catholic births, while half of all births assisted by Maria Nagy were those of Orthodox women.

In the mountain communities, for example in Muntele Rece, in the county of Cluj, we can barely find a woman who has not assisted, at least once, a relative or neighbour in labour. Muntele Rece was a relatively small community, of under 1,000 inhabitants, and yet it registered 360 midwives in the period of time under investigation. Only 2 of them have more experience, which proves that their skills were recognised by the whole community, even though they may not have had a certificate to prove their expertise. The specific geographical conditions - the village being situated on a mountain top, with great distances between houses - made difficult the presence of an 'official' midwife, particularly in the snow-covered half of the year. Thus, the women gave birth assisted by whoever happened to be nearby.

In the 19th century there was an increase in the authorities' efforts to cover the province with much-needed medical personnel and hospital centres. Unfortunately, to this date, there are no systematic researches which analyse the question of medicalisation in Transylvania, in particular in regards to its beginning. The reason behind this informational gap is, first and foremost, the lack of primary sources. All attempts at discovering the archives of medical institutions and those of the schools which formed/instructed the medical personnel, as well as the medical reports sent from Transylvania to Budapest, have been unsuccessful.

Analysing the legislation issued by the Habsburg (and later Austro-Hungarian) Empire, it can be seen that the authorities, counselled by the outstanding medical personalities of the era, were aware of the need to spread the scientifically based medical practices, of the urgency to ensure some control over the medical services provided by countless healers and the necessity of intervening in poorly literate, superstitious and ignorant communities in order to reduce the high mortality. Infant mortality and maternal mortality were the causes which determined the state's intervention in what we now call 'the medicalisation of birth'. The state issued laws on the basis of which the local authorities were obliged to take measures towards the creation, organisation and good functioning of medical education - regardless of whether it concerned the training of doctors, surgeons, pharmacists and midwives, or the attracting of students towards these institutions. It was also the local authorities' duty to ensure that communities accepted the help of these specialised services in the place of those they had been used to. Scholarships were offered, tuition and transportation fees were covered - anything that worked so that women who fitted the criteria could be trained into providing qualified childbirth assistance. Until the outbreak of the First World War, over 2,000 Transylvanian women had earned the right to practise the midwife profession. The establishment of the Medicine Institute at Cluj, in 1775 , brought with itself the first courses certifying the profession of midwife. Later on, in 1809, a second medical school was established in Sibiu and only towards the end of the century did other Transylvanian towns open medical training institutions of their own.

Nevertheless, not only is the number of trained midwives smaller in Transylvania than in other regions of the Austro-Hungarian Empire, but even the few trained midwives are not always found practicing their profession, as shown by the statistics of the Ministry of Cults and Public Instruction. A much higher influx of 
German and Hungarian women can be noticed, whereas the presence of Romanian women (Orthodox and Greek (atholic) was rather reduced. The explanation for this reality is the low level of literacy on one hand, and these communities' firm belief in their millennial traditions on the other. The doctor — or the trained medical personnel — is accepted with difficulty in these communities, particularly in situations as intimate as the birthing of a child.

The data included in HPDT confirms that, at the turn of the century, the medicalisation of birth was not even nearly as widespread a process as one might be inclined to believe when seeing the official statistics. Over $80 \%$ of the women included in our sample were 'handywomen', not 'diplomatic midwives'. It can also be said that the medicalisation under all its aspects, including the birth, went hand in hand with the processes of modernisation and industrialisation. The example of the Ocna Mureş community is very relevant. In this place, where the community paid for the midwives' services, the women made use of their help and expertise - regardless of ethnicity and religion. Language and faith were not seen as barriers towards a safe birth assisted by an official midwife; they were actually preferred to the empirical midwives, who had their price as well. Further data, which we hope to find in the archives in Budapest, will help us to better understand the process of medicalisation of birth in Transylvania. Also, the differences in child and maternal mortality according to the different types of care (professional or traditional) would help us to analyse the effects of training.

\section{REFERENCES}

Dumănescu, L. \& Eppel, M. (2019). The politics of birth in a composite state: Midwives in Transylvania (19th20th Century). Romanian Journal of Population Studies, 13(1), 7-28. doi: 10.24193/RJPS.2019.1.01

Holom, E. C, Sorescu-ludean, O., Hărăguş, M. (2018). Beyond the visible pattern: Historical particularities, development, and age at first marriage in Transylvania, 1850-1914. The History of the Family, 23(2), 329-358. doi: 10.1080/1081602X.2018.1433702

Mandemakers, K., \& Dillon, L. (2004). Best practices with large databases on historical populations. Historical methods, 37(1), 34-38. doi: 10.3200/HMTS.37.1.34-38 